\title{
A PROSPECTIVE STUDY OF FUNCTIONAL OUT COME OF DISTAL FEMUR FRACTURE WITH INTRA ARTICULAR EXTENSION USING NEWER RAINA`S APPROACH WITH BICOLUMN PLATING
}

\section{Original Article Orthopaedics}

Ashokan. $\quad \mathbf{C}^{1}, \quad$ Kathirazhagan. $\mathbf{S}^{2}$, Parasuraman. $\mathrm{K}^{3}$

1 - Associate Professor, Department of Orthopaedics, Stanley Medical College

2 - Senior Resident, Department of Orthopaedics, Tagore Medical College

3 - Assistant Professor, Department of Orthopaedics, Rajah Muthiah Medical College

Corresponding Author:

Dr. Parasuraman. K.

Assistant Professor, Department of Orthopaedics, Rajah Muthiah Medical College

Article submitted on: 24 February 2019 Article Accepted on: 25 February 2019

\begin{abstract}
Management of distal femur fractures has evolved from conservative treatment resulted in mal alignment \& immobilizations and associated complications, the surgical methods promoted $A O$ internal fixation to regain the full functional range of movements, the conventional approach for distal femur fractures with intra articular extension is through the lateral approach the exposure of intra articular fracture fragments is difficult, other surgical approaches have been reported for distal femur fractures with intra articular extensions but all of them have own limitations. In Olerud using extensible midline $Y$ incisions with elevation of tibial tubercles, the exposure to the intra articular fragments is adequate but chances of tibial tuberosity nonunion and skin necrosis is high, swashbuckler approach is an antero- lateral approach provides inadequate approach to medial condyles. In our study we would like to assess the functional outcome of Raina's approach for reconstruction of distal femur fractures
\end{abstract}




\section{Introduction}

Distal femur fracture involves the metaphysis of femoral condyles, distal femur fractures are less frequent than hip fractures, the incidence of distal femur fractures representing $4-6 \%$ of overall femoral fractures, intra articular extension of distal femur fractures occurs approximately $1 / 10^{\text {th }}$ of proximal femoral fractures. Fractures in young patients after high velocity injury especially by the road traffic accidents by frontal collision mechanism, In elderly patients sustained fracture after low velocity trauma due to osteoporotic bone, in both these categories management remains challenging for surgeons. Intra articular fracture of distal femur occurs after high energy trauma, these fractures are difficult to treat because of associated severe soft tissue damage, communition, patellar fractures, potential to produce deformities \& long term disabilities, no single surgical procedure has overcome all problems associated with distal femur fractures.

Management of distal femur fractures has evolved from conservative treatment resulted in mal alignment \& immobilizations and associated complications and the surgical methods promoted $\mathrm{AO}$ internal fixation to regain the full functional range of movements

The choice of surgical treatment has been evolving due to advances in implant designs, fracture reduction tool, improved surgical techniques and increased functional demand of the patients, the choice of implants from dynamic condylar screw to locking compression condylar plate, the conventional approach for distal femur fractures with intra articular extension is through the lateral approach the exposure of intra articular fracture

fragments is difficult, other surgical approaches have been reported for distal femur fractures with intra articular extensions but all of them have own limitations. In Olerud using extensible midline $\mathrm{Y}$ incisions with elevation of tibial tubercles, the exposure to the intra articular fragments is adequate but chances of tibial tuberosity nonunion and skin necrosis is high, swashbuckler approach is an antero lateral approach

\section{Materials and methods}

\begin{tabular}{|l|l|}
\hline Study Topic & $\begin{array}{l}\text { A prospective study of functional out come of distal femur } \\
\text { fracture with intra articular extension using newer raina`s } \\
\text { approach with bicolumn plating }\end{array}$ \\
\hline Study Design & Prospective study \\
\hline Study Venue & $\begin{array}{l}\text { Department of Orthopaedics, Government stanley Medical } \\
\text { college and Hospital, chennai-1. }\end{array}$ \\
\hline Period of Study & june 2015 to april 2017 \\
\hline Sample size & Twenty patients \\
\hline
\end{tabular}

\section{Inclusion criteria}

1) Patient with distal femoral fractures which needs to be internally fixed in Muller's type $\mathrm{C}$ fractures.

2) Age more than 16 years.

3) Patient with compound grade I, grade II.

\section{Exclusion criteria}

1) Skeletal immaturity with open physis.

2) Muller's type B \& type A fracture.

3) Patient with compound grade III

4) Patients not willing for surgery.

5) Pathological fractures.

6) Periprosthetic fractures.

\section{Pre Operative Protocol}

\section{Examination}

A thorough clinical examination was done as per protocol which included age, sex, occupation, mode provides inadequate approach to medial condyles. Hence I would like to study this newer Raina's approach for reconstruction of distal femur fractures

\section{Aim \\ The aim of the study is to analyze the functional outcome of distal femur fracture with intra articular extension using newer Raina's approach using bicolumn plating}

of injury, type of fracture, time interval between injury and surgery, associated comorbid conditions and other associated injuries.

Investigations

Routine investigations like Haemogram, Blood sugar, Urea, Creatinine, Serum electrolytes, Xray Chest, ECG, BT, CT was done. Medical and anaesthetic fitness for all the patients before surgery.

\section{X-Rays}

X-ray Femur AP / Lateral view from the knee to proximal femur was taken for all the 20 cases and following features were assessed: Type of fracture, Amount of Comminution, Articular congruence and Quality of bone. All other requisite Xrays to rule out associated injuries were also taken.

Step-by-step surgical sequence for Distal Femur LCP fixation 


\section{Preoperative Selection of Implants}

The preoperative $\mathrm{x}$-ray is used to determine the length of the LCP and the position of the screws. To measure the length of the condylar screw, the Maximum condylar width on the radiograph is determined to determine the real condylar width.

\section{Patient Position}

Patient is positioned in supine position on the operating table with a sandbag under the ipsilateral buttock to elevate the buttock and sterilebolsrer is kept under the knee to counter femor condyle deformity ie, hyperextensions.

Surgical Approach-Midline Newer Raina's approach

\section{General Considerations}

This approach to the distal femur provide adequate exposure of articular surface, medial column and lateral column, metaphysis of distal femur. It allows anatomical reductions and bicolumn plating which provides early mobilizations and prevent the varus collapse.

\section{Prophylactic antibiotics}

We used third generation cephalosporin for prophylactic antibiotic cover for both open and closed fractures

\section{Skin Incision}

Make a longitudinal midline skin incision extending from a point $10 \mathrm{~cm}$ above the superior pole of patella inferiorly upto the level of tibial tubercle. Proximal extension of skin incision depends on the proximal extend of the fracture.

\section{Dissections}

There is no internervous plane to this approach, skin incision is extended superiorly, subcutaneous tissue incised and achieve the hemostasis. Make a $\mathrm{V}$ shaped osteotomy in the junction of upper $2 / 3^{\text {rd }}$ and lower $1 / 3^{\text {rd }}$ of patella done using saw. Medial and lateral retinaculum are incised and arthrotomy done. Lateral arthrotomy extended superiorly to the lateral intermuscular septum above the fracture site after cutting the iliotibial band and medial arthrotomy wound extended upto upper pole of patella. Entire extensor mechanisms along with patella retracted medially and exposing the fracture sites.

All the fracture fragments are identified and ends are freshened and reduced with preliminary $\mathrm{K}$ wires and converting into one fragment pointed reduction clamp is used to reduce the condyle indirectly. Avoid releasing the soft tissue attached to the fragments and reconstruct the articular surface of the distal femur. If the bone loss in the articular surface filled with bone graft, minimal traction is applied and sand bag below the femur allow the reduction of the supracondylar fragment of the distal femur with proximal fragment, $\mathrm{K}$ wire in the condyle place is not hindering the plate position. Prefixed k wires are drilled with $2.5 \mathrm{~mm}$ cannulated drill bit and fixed with $4 \mathrm{~mm}$ cannulated cancellous screw to convert the stable single condyle of the distal femur.

\section{LCP Insertion}

Distal femur locking compression plate is placed over the lateral surface of the femur. The implant is precontoured and anterior curvature of the femur to accommodate the plate. The fixation bolt is oriented to the patellar femoral surface, it has to be optimal fitting on the bone. Lcp usually 1 to $1.5 \mathrm{~cm}$ superior to articular surface of femoral condyle and approximately 1 to $1.5 \mathrm{~cm}$ superior to articular surface of femoral condyle, the condyles are fixed with $6.5 \mathrm{~mm}$ locking head screw of appropriate size and the position of plate and reduction are maintained till proximal fragment fixation, reduction and plate off set is maintained indirectly by bone reduction clamp, plate are fixed to shaft with locking and non locking cortical screw

Finally contoured medial plate ( $1 / 3^{\text {rd }}$ tubular plate) for medial column continuity fixed with cortical screw of 2 or 3 proximally and distally this allow stable fixation to prevent varus collaps

Osteotomy of patella was fixed with two parallel $\mathrm{k}$-wire at junction of anterior $1 / 3^{\text {rd }}$ to posterior $2 / 3^{\text {rd }}$ and 18 guage ss wire is inserted in the form of fig of 8 on the principle of modified tension band wiring, arthrotomy wound are closed with negative suction drain.

\section{Post Operative Care And Rehabilitation}

Rehabilitation is very essential to attain a range of motion, strength and function of the knee. Rehabilitation is based on stability of fixation. The most useful range of motion can be achieved in the 6 to 8 wks of postoperative period.

Early Phase (1-3 Weeks)

Moblization exercises are starts on 2nd day as tolerated by the patient.

Quadriceps and hamstring stretching exercises

Non - weight bearing (crutches or walker support) can be initiated in 1st week, if fixation is stable.

\section{Late Phase (After 3weeks)}

- Isometric quadriceps exercises, Active and passive Range motion exercises are continued.

- Seated knee extension exercise.

- Partial weight bearing is begin 
after 6th week.

- $\quad$ Full weight bearing is allowed after radiological evidence of healing.

\section{Goals Of Rehabilitation}

- About $65^{\circ}-70^{\circ}$ flexion is

required for swing phase of gait.

- About $90^{\circ}$ flexion is required for ascend and descend stairs.

- About $105^{\circ}$ flexion is required to rise early from a low chair and to tie one's shoes.

\section{Case Illustrations}

\begin{tabular}{|l|l|}
\hline Name & R \\
\hline Age/Sex & $49 /$ Male \\
\hline Mode of Injury & RTA \\
\hline Side & left \\
\hline Associated Injury & None \\
\hline Associated Comorbidity & None \\
\hline Muller's Type & Closed Type C2 Fracture \\
\hline Time Interval for Surgery & 18 days \\
\hline Time for Radiological Union & 13 weeks \\
\hline Knee Flexion Achieved & 115 o \\
\hline Functional Outcome & Excellent \\
\hline
\end{tabular}

\section{Case 1}
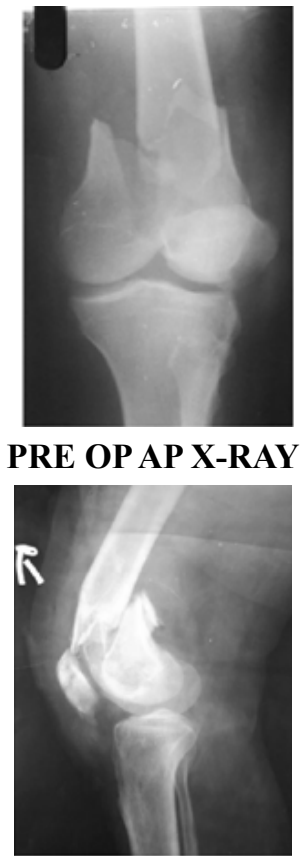

PRE OP LATERAL X-RAY

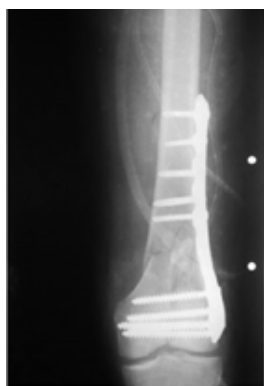

POST OP AP X-RAY

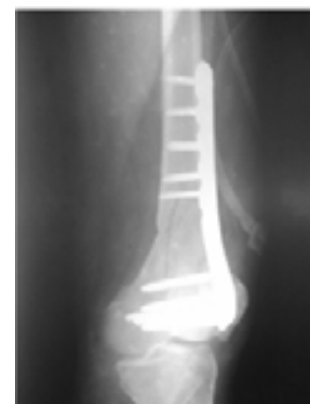

POST OP LATERAL X-RAY

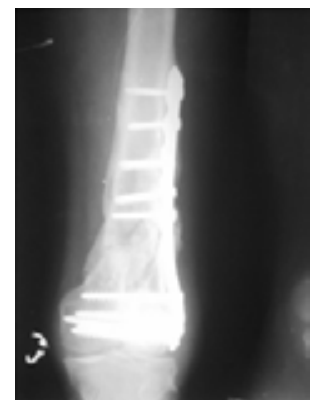

6 MONTHS FOLLOW UP

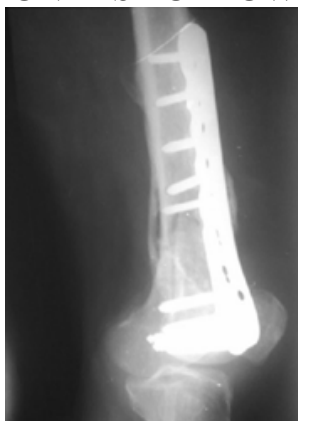

6 MONTHS FOLLOW UP

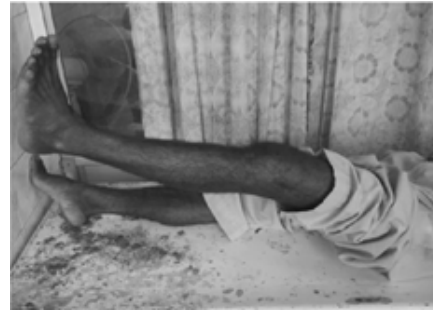

KNEE EXTENSION

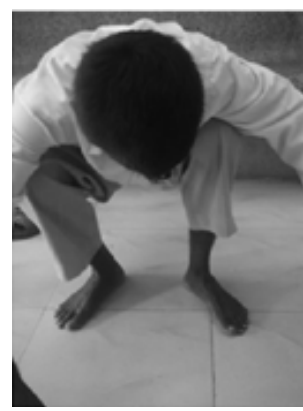

KNEE FLEXION

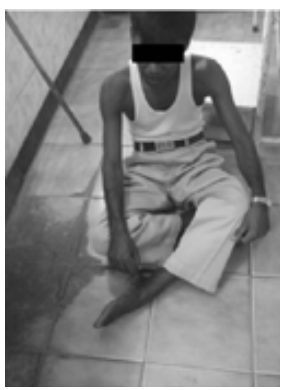

CROSS LEG SITTING

\section{Results}

KNEE SOCIETY SCORING SYSTEM used to assess the outcome of distal femoral fractures managed with bicolumn platting its based on the clinical parameters \&Functional Score based on patient perceives that knee functions with specific activities.

Overall results were excellent in 11 out of 20 cases and were good to fair in 7 cases. The outcome was poor in 2 cases. The overall mean score in our study was 76.6 units. 
Overall Results

\begin{tabular}{|l|c|c|}
\hline \multicolumn{1}{|c|}{ Grading } & No. of Cases & Percentage \\
\hline Excellent & 4 & 20 \\
\hline Good & 9 & 45 \\
\hline Fair & 4 & 20 \\
\hline Poor & 3 & 15 \\
\hline
\end{tabular}

Results According to Subtype

\begin{tabular}{|l|l|l|l|l|}
\hline $\begin{array}{c}\text { Mullers } \\
\text { Subtype }\end{array}$ & Excellent & Good & Fair & Poor \\
\hline C1 & 0 & 3 & - & - \\
\hline C2 & 3 & 5 & 1 & 2 \\
\hline C 3 & 1 & 1 & 3 & 1 \\
\hline
\end{tabular}

\section{Complications}

The following complications may be expected for distal femur fractures.

Early complications are

\section{Iatrogenic fractures, especially in osteoporotic bones.}

1. Iatrogenic injury to medial and lateral collateral ligaments and menisci.

2. Damage to popliteal vessels, (very rare.)

3. Damage to geniculate vessels and accompanying nerves.

\section{Late}

1. Infection

2. Loss of Reduction, due to improper surgical techniques.

3. Poor patient compliance

4. Nonunion, Malunion in varus \& valgus position, varus malalignment $>10^{\circ}$ and $/$ or rotational deformity $>15^{\circ}$, should be corrected.

5. Knee stiffness

6. Secondary osteoarthritis if articular incongruity is present Of all the early complications, we didn't encountered early complication.

Late complications ,I encountered superficial infection occurred in one case, which was a compound fracture grade II and patient had comorbits of type 2 diabetes mellitus and it was treated with parenteral antibiotic after identifying the organism. Patient had union and functional outcome was fair

Apart from that, 2 patients had deep infection only \& knee stiffness one patient was compound grade II fracture and one patient was closed fracture ,both patient developed discharge from the wound after 2 rd wks, initially it was treated with parenteral antibiotics after identifying the organism and subsequent wound wash was given inspite of that infection was persistent ,hence implant exit was done on $13 \&$ 16 wks respectively after bone union subsequently, patient develop knee stiffness because fracture protected with functional cast , and functional out come was poor

Of all late complication one patient develop non union patella, which was associated with communited patella fracture with compound grade II wound ,managed with cerclage ,patient started early mobilization ,fragments were displaced and patient was poor compliance and functional score was poor.

\section{Discussion}

The distal femur fracture with intra articular extension fixation with bicolumn based on principle $\mathrm{AO}$ fracture fixation, the prognosis factors include age, method of treatment, intra articular involvement,and timing of joint mobilization,etc

\section{Major contributing fractor}

1 improper fixation due to complexity of fracture comminution

2 elderly patient (less motivation to begin exercise, low osteogenic potential)

3 delay in surgery

4 open/closed fracture

\section{Age wise distribution}

Most of the patients in this study were from 3 to 6 decade of life.

Mean age in this group was 47.2

\section{Sex distribution:}

In our study most of the patient was male $85 \%$ and $15 \%$ were female, most outdoor activities were male as compared with female.

RUJ et al, treatment of distal femur fracture-less invasive stabilization system. This study shows similar results

\section{Mode of injury}

In this study, the mode of injury of the patients were RTA and accidental fall.

RTA accounts for about $80 \%(16)$ of total injury, were accidental fall for about $20 \%$ (4) of total injury.

Marinet $\mathrm{o}$, et al epidemiology of fracture of distal femur study shows similar results

RTA is due to direct trauma to the knee or fall from height

\section{Side wise distribution}

We have studied 20 cases of distal femur fracture, amongst that 14 were left side and 6 were right

RUJ et al, treatment of distal femur fracture-less invasive stabilization system. This study shows similar results 


\section{Associated injuries}

In this study, 3(15\%) patients have associated medial meniscus tear and the

\section{Time since injury}

In this study, the mean interval for surgery is 20 days

\section{Complications}

In our study, superficial wound infection was seen in 5\% and deep infection and knee stiffness $10 \%$ and

\begin{tabular}{|l|c|c|c|}
\hline & N & Mean & Maximum \\
\hline Excellent & 4 & 120.00 & 125 \\
\hline Good & 9 & 110.00 & 115 \\
\hline Fair & 4 & 96.25 & 100 \\
\hline Poor & 3 & 63.33 & 70 \\
\hline Total & 20 & 102.25 & 125 \\
\hline
\end{tabular}

In type $\mathrm{C}$ fracture :intra articular fracture reduced anatomically and extra articular that needs restoration of alignment without true anatomical reduction

If there is a metaphyseal communition fracture prone for varus collaps hence need of medial plating to prevent the complication of varus mal union.

The newer approach has advantage of complete true anatomical reduction and facilitation of $\mathrm{k}$ wire fixation from all direction in distal end of femur, preservation of suprapatellar pouch of fat pad its help in fracture union and prevent quadriceps adhesion, after extensor mechanism reflected ,comfortable application of plate in medial side,allow the bone grafting for bony defects in all location, addressing internal derangement of knee and also valuable in revision surgery

\section{Conclusion}

Type c distal femur fracture presents a challenging problem to any orthopaedic surgeon. non union patella were $5 \%, 80 \%$ were presented with no complication

\section{Functional outcome}

In the post operative functional outcome of distal femur fracture were measured by knee society scoring system

In our study 3 patients were $\mathrm{C} 1$ types and 11 patient were CII TYPE and 6 patient were CIII type, average achived knee flextion $102.2^{\circ}$

1. Olerud described the extensile approach for the type $\mathrm{c}$ fractures, the main complication is wound healing and restricted range of movements of knee.

2. We try the this newer approach to overcome the problems related to the type $\mathrm{c}$ fractures by internal fixation, through modification of the extensile oleurd approach( newer Raina's approach), anatomical reduction of the articular fragments, usage of LCP plate and medial buttressing plate for augumentation of bone defects, preservation of suprapatellar pouch of fat pad, early aggressive rehabilitation.

3. LCP is the implant of choice for distal femur fractures in elderly patients because of osteoporotic bone, this provides a early rehabilitation and leads to better post operative functional outcome

4. For all these patients early rehabilitation and aggressive post op protocol should be followed for better functional outcome.

5. In previous studies of type c fractures shows average knee flexion was 105 degrees which were similar to our study results, and complication rates were also similar to our study.

6. The use of intra operative image intensifier is nil in our study, where through other approaches the image intensifier plays a major role in anatomical reconstruction of articular surfaces. So our approach can be done in secondary care centers.

7. In previous studies without medial plating the rates of varus collapse and non union were high but in our study the usage of medial plating has not yielded any case of malunion or varus deformity.

8. In our study though there were complications the union rates and functional range of movements were excellent and good in $65 \%$ of cases, so modified Raina's approach is one of the better approaches to achieve anatomical reduction, bony union and better functional outcome in type $\mathrm{c}$ distal femur fractures.

9. The study of larger magnitude will reveal the advantages and disadvantages which were not apparent in this study.

\section{References}

1. Jazrawi LM, Kummer FJ, Simon JA, Bai B, Hunt SA, Egol KA, Koval KJ (2000) New technique for treatment of unstable distal femur fractures by locked double-plating: case report and bio- 
mechanical evaluation. J Trauma 48(1):87-92

2. Sanders R, Swiontkowski M, Rosen H, Helfet D (1991) Doubleplating of comminuted, unstable fractures of the distal part of the femur. J Bone Joint Surg Am 73(3):341-346

3. Mu"ller ME (1991) Appendix A. The comprehensive classification of fractures of long bones. In: Mu"ller ME, Allgo"wer M, Schneider R, Willenegger $\mathrm{H}$ (eds) Manual of internal fixation, 3rd edn. Springer, New York, pp 118 150

4. Gwathmey FW Jr, Jones-Quaidoo SM, Kahler D, Hurwitz S, Cui Q (2010) Distal femoral fractures: current concepts. J Am Acad Orthop Surg 18(10):597-607

5. Olerud S (1972) Operative treatment of supracondylar-condylar fractures of the femur. Technique and results in fifteen cases. J Bone Joint Surg Am 54(5):1015-1032

6. Kim JW, Oh CW, Kyung HS, Min WK, Yoon SH (2009) Factors affecting the results of distal femoral fractures treated by retrograde intramedullary nailing. Zhongguo
Xiu Fu Chong Jian Wai Ke Za Zhi 23(11):1311-1315

7. Pro"bstel M, Bo"rner M (2000) Technical problems following operative treatment of supracondylar femoral fractures. Acta Chir Austriaca 32(161):85-87

8. Arazi M, Memik R, Ogün TC, Yel M (2001) Ilizarov external fixation for severely comminuted supracondylar and intercondylar fractures of the distal femur. $\mathbf{J}$ Bone Joint Surg Br 83(5): 663667

9. Ali F, Saleh M (2000) Treatment of isolated complex distal femoral fractures by external fixation. Injury 31(3):139-146

10. Hutson JJ Jr, Zych GA (2000) Treatment of comminuted intraarticular distal femur fractures with limited internal and external tensioned wire fixation. J Orthop Trauma 14(6):405-413

11. Ramesh LJ, Rajkumar SA, Rajendra R, Rajagopal HP, Phaneesha MS, Gaurav S (2004) Ilizarov ring fixation and fibular strut grafting for C3 distal femoral fractures. J Orthop Surg (Hong Kong) 12(1):91-95
12. Cavusoglu AT, Ozsoy MH, Dincel VE, Sakaogullari A, Basarir K, Ugurlu M (2009) The use of a low-profile Ilizarov external fixator in the treatment of complex fractures and non-unions of the distal femur. Acta Orthop Belg 75(2):209-218

13. Mize RD, Bucholz RW, Grogan DP (1982) Surgical treatment of displaced, comminuted fractures of the distal end of the femur. $\mathrm{J}$ Bone Joint Surg Am 64:871-879

14. Borse V, Hahnel J, Cohen A (2010) Hoffa fracture: fixation using headless compression screws. Eur J Trauma Emerg Surg 36(5): 477-479

15. Baker BJ, Escobedo EM, Nork SE, Henley MB (2002) Hoffa fracture: a common association with high-energy supracondylar fractures of the distal femur. Am J Roentgenol 178(4):994

16. Koval KJ, Hoehl JJ, Kummer FJ, Simon JA (1997) Distal femoral fixation: a biomechanical comparison of the standard condylar buttress plate, a locked buttress plate, and the 95-degree blade plate. $\mathrm{J}$ Orthop Trauma 11(7):521-524. 